\title{
End-member volcanism in the absence of plate tectonics: Silicic volcanism on the Moon.
}

A White Paper submitted to the Planetary Science and Astrobiology Decadal Survey 2023-2032

Primary Authors:

Sarah N. Valencia

University of Maryland College Park/NASA Goddard Space Flight Center sarah.n.valencia@nasa.gov

Ryan N. Watkins

Planetary Science Institute

rclegg-watkins@psi.edu

Co-Authors:

Jacob A. Richardson, University of Maryland College Park/NASA Goddard Space Flight Center Timothy Glotch, Stony Brook University

Erica Jawin, Smithsonian Institution National Museum of Natural History

Srinidhi Ravi, Arizona State University

Brad L. Jolliff, Washington University in St. Louis

Signatories:

Kerri Donaldson Hanna, University of Central Florida Briony Horgan, Purdue University

Jessica Flahaut, CNRS/CRPG Nancy

Samuel Lawrence, NASA Lyndon B. Johnson Space Center and LEAG Chair

Indhu Varatharajan, DLR Institute of Planetary Research Daniel P. Moriarty III, NASA GSFC / USRA

Lauren M. Jozwiak, Johns Hopkins University Applied Physics Laboratory 
Through decades of study of lunar samples and observations from modern remote sensing missions, we know highly silicic rocks occur on the Moon, but that they are relatively rare. The occurrence of silicic magmatism on the Moon is enigmatic and fascinating given that the key ingredients that are common in producing silicic melts on Earth (i.e., water and plate tectonics) are absent in the lunar environment. Silicic volcanism represents an end stage in magmatic evolution and studying these rocks is important for our understanding of thermal evolution and volatile-element behavior, and concentration of strategically important trace elements. However, given that silicic rocks are among the rarest in the lunar sample collection, and none were taken in place, we lack the geologic context to tie sample observations to data collected by remote sensing. Thus, the topic of silicic volcanism on the Moon is critically in need of targeted studies to answer outstanding questions about the evolution of the lunar interior and how silicic magmatism occurs on one-plate planets in our solar system.

\section{Background}

Granites and granitoid rocks are evolved igneous rocks that occur on silicate (i.e., $\mathrm{SiO}_{2}$ bearing) planetary bodies when highly silicic melts (i.e., rich in $\mathrm{SiO}_{2}$ ) form as residual melts of more mafic parent melts, or by partial melting of "fertile" crustal rocks (Winter, 2014). Owing to the large knowledge gaps that remain about non-basaltic magmatism on the Moon, for this paper we use the broad term "silicic" to include all rocks considerably richer in $\mathrm{SiO}_{2}$ than lunar basalts. Silicic rocks can either be intrusive (i.e., plutonic: diorite, granodiorite, or granite) or extrusive (i.e., volcanic: andesite, dacite, or rhyolite). On Earth, silicic rocks are common and span a large range of compositions. Highly silicic rocks on Earth (i.e., granite/rhyolite) are efficiently created by subduction, which recycles crust and concentrates $\mathrm{SiO}_{2}$ in magma through partial melting and extended fractional crystallization, though other petrogenesis pathways for silicic rocks exist.

Unlike Earth, highly silicic rocks are relatively rare on the Moon. While a few fragments of silicic rocks or mineral assemblages were returned by the Apollo missions, none of the Apollo or Luna missions visited a silicic target, thus our knowledge of these enigmatic terrains relies mostly on remote sensing observations. Many of these remotely sensed areas are classified as spectral "red spots" Whitaker (1972) and are characterized by high albedos, strong absorptions in the UV, and morphologic characteristics such as domes with steep flanks, consistent with silicic volcanic constructs (e.g., Hagerty et al., 2006). Morphometric studies of these landforms estimate yield strengths and plastic viscosities that are characteristic of silicic lavas (Wilson and Head, 2003). These remote observations indicate there are significantly large silicic bodies on the Moon, thereby motivating the need for targeted studies of silicic rocks on the Moon including additional remote observations and sample studies (Valencia et al., 2020).

\section{Possible Formation Mechanisms of Silicic Rocks on a One-Plate Body}

Volcanism on the Moon is hypothesized to be dominated by short-lived, voluminous basalt outpourings from large dikes (Wilson and Head, 2017), owing to the difficulty of sustaining melt in a relatively cool crust and a lack of buoyant forces driving smaller magma bodies toward the surface. These factors make granite formation at colder and/or smaller planets difficult, and we have a poor understanding of the mechanisms through which silicic rocks from. Constraining the conditions under which silicic melts were produced is essential to understanding the thermal evolution of the Moon.

There are two leading formation hypotheses for silicic lithologies on the Moon - silicate liquid immiscibility (SLI) and basaltic underplating. SLI occurs when a basaltic magma basaltic magma 
undergoes $>90 \%$ fractional crystallization. The basaltic magma splits into two coexisting, yet immiscible, melts - one of which is enriched in $\mathrm{SiO}_{2}$ and the other in $\mathrm{FeO}$. The $\mathrm{SiO}_{2}$ rich melt, being less dense, erupts at the surface to form silicic volcanic landforms or cools to form intrusive silicic bodies. Another process capable of producing silicic assemblages is partial melting induced by basaltic underplating (Hagerty et al., 2006; Gullikson et al., 2016). The first or minimumtemperature melt in the silica-plagioclase-pyroxene system would have a granitic composition. If a sufficiently fertile rock, i.e., one that would produce a significant amount of silicic melt at low temperature, were to undergo partial melting, the melt would be granitic, and if a sufficient volume were produced, would be positively buoyant and rise through the country rock undergoing melting. Sufficiently fertile crustal rocks include KREEP (explained in detail in next section) basalt (a volcanic rock) or monzogabbro (also called monzodiorite), which are intrusive equivalents or fractionates of KREEP-basalt-like parent magmas.

\section{Observations from Apollo Samples}

Only about 20 silicic samples were returned from the lunar surface from the Apollo 12, 14, 15, and 17 missions (summarized in Seddio et al., 2013). These samples occur as small fragments from the regolith or as clasts in breccia. The largest silicic-bearing sample returned from the Moon is only $82.3 \mathrm{~g}$, meaning our collection of silicic lunar rocks is small. In addition to not having been collected in place, and it is unclear how representative these samples are of the large silicic bodies that have been detected from orbit. Below, we briefly summarize the mineralogy and chemistry of the samples and how they inform our models of silicic volcanism.

\section{Overview of the Silicic Samples}

The silicic Apollo samples are granitic in composition - no large clasts of andesite or dacite have been found to date. These granites are dominated by fine-grained assemblages of silica and K-feldspar (i.e., felsite). Accessory minerals such as ferropyroxene, relatively Na-rich plagioclase, fayalite, ilmenite, zirconolite, apatite, and merrillite (Seddio et al., 2013) may occur. One of the many reasons it is important to study silicic samples is because of their association with KREEP As the lunar magma ocean solidified, the remaining magma became enriched in incompatible elements such as potassium (K), rare earth elements (REE), and phosphorus (P), also known as KREEP (Hubbard et al., 1971). Pockets of KREEP-rich magmas became sandwiched between the crust and mantle and may have played a role, either as an assimilant or a heat source, with volcanism on the nearside. Lunar granites are enriched in KREEP elements, and particularly important, in Thorium (Th; $>50$ ppm), a highly incompatible element that concentrates in KREEP. Thorium is commonly used as a proxy for KREEP because it can be easily detected from orbit (Reedy, 1978; Lawrence et al., 2003) and, therefore, provides one of the ways we can connect sample data to current remote sensing data.

\section{Implications of Sample Observations on the Formation of Lunar Granite}

In some Apollo samples, granitic segregations occur with or within a more mafic assemblage of monzogabbro, sometimes referred to as monzodiorite. In several Apollo samples, the granitic segregations have rounded, bleb-like morphologies that are clear indicators of formation by SLI( e.g., Jolliff et al., 1999), as are small silicic segregations in mesostasis of some mare basalts (Roedder and Weiblen, 1972). The compositions of the rocks and minerals can be modeled using phase relationships, and are clearly products of SLI. That SLI could and did occur within some lunar rocks, resulting in small silica and K-feldspar segregations, is not in question. Whether 
this process is how all lunar granitic assemblages formed, however, is not at all clear. As indicated above, lunar granitic samples are invariably enriched in the trace-element Th. This enrichment is not consistent with trace-element partitioning experiments, which indicate that during SLI, Th enters the FeO-rich phase (e.g., Gullikson et al., 2016). Thus, to produce silicic magmas on the Moon, some process other than SLI must have been involved. Moreover, the small amounts of silicic material produced by SLI would have to concentrate, presumably by gravity segregation, in a very efficient manner and from a very large volume of nearly crystalline rock in order to source large volcanic constructs such as the Gruithuisen Domes. Such segregation is difficult to envisage owing to the very high viscosity of granitic melt, especially if relatively dry, as indicated by the mineralogy of the samples.

Partial melting owing to basaltic underplating, however, may explain the chemistry of the silicic lunar samples. Modeling of the melts formed by partial melting, induced by basaltic underplating from mantle-derived basalts, reproduces some of the trace element (particularly Th) characteristics of lunar granite (Gullikson et al., 2016). Physical association of silicic clasts with basaltic clasts in Apollo 12 sample 12013 also lends support for the bimodal volcanism that would occur in the basaltic underplating model (Valencia et al., 2019). Thus, evidence from the Apollo samples demonstrate that partial melting by basaltic underplating is a likely path for the formation of silicic bodies on the Moon, but SLI also occurs at some level.

\section{Observations of Silicic Rocks from Remote Sensing}

An array of evidence from remote sensing missions exists - primarily the Lunar Prospector Gamma Ray Spectrometer, the Lunar Reconnaissance Orbiter (LRO) Diviner instrument, and LRO imagery - to support the presence of large-scale occurrences of silicic volcanic rocks on the Moon. The current state of observations is summarized below, as well as the implications these observations have on the formation of silicic magmas on the Moon.

\section{Overview of Modern Remote Observations}

Lunar Prospector - The Lunar Prospector Gamma-Ray Spectrometer (LP-GRS) measured Th abundances across the lunar surface, revealing several Th "hotspots" that correlate with known red spots (e.g., Lawrence et al., 2003). Combined with our knowledge of sample compositions, it can be assumed that areas of high Th concentration on the Moon are indicators of silicic materials. Hagerty et al. (2006) used LP-GRS Th data and morphology to suggest that red spots such as Hansteen Alpha and the Gruithuisen Domes were formed by viscous, silicic magmas similar to terrestrial rhyolites. These landforms exhibit a Th abundance $(>50 \mathrm{ppm})$ comparable to evolved lithologies such as quartz monzogranites (QMGs) in the lunar sample suite. Thorium concentrations for the Compton-Belkovich Volcanic Complex (CBVC) could be as high as 40-55 ppm, consistent with the Th concentrations measured in lunar granites (Jolliff et al., 2011).

Lunar Reconnaissance Orbiter Diviner - The LRO Diviner Lunar Radiometer Experiment has identified silicic compositional anomalies at Hansteen Alpha, the Gruithuisen Domes, the Mairan Domes, the Lassell Massif, CBVC, Aristarchus crater, and Herodotus Mons, a small dome partially buried by pyroclastic deposits on the Aristarchus plateau (e.g., Glotch et al., 2010; Jolliff et al., 2011; Greenhagen et al., 2010). Each of these features, with the exception of Aristarchus crater, are extrusive volcanic constructs with steep slopes, high visible albedos, and anomalous visible/near-infrared and thermal infrared spectral properties. Aristarchus, by contrast, has exposed a subsurface granitic pluton. Diviner has also identified a number of features that exhibit similarities to these silicic regions, but with weaker spectral signatures. These weaker signatures 
could be owing to mixing with surrounding mafic terrain or the presence of intermediate (i.e., andesite) compositions (Greenhagen et al., 2017).

Silicic anomalies are identified in Diviner Christiansen feature (CF) data via a concave up spectral shape. The CF is an emissivity maximum that occurs near $8 \mu \mathrm{m}$, and the position is related to mineral/rock composition, with mafic compositions having longer wavelength $\mathrm{CF}$ positions than felsic compositions (Greenhagen et al., 2010). The CF positions of highly silicic rocks (e.g., granite, rhyolite, and dacite) occur at wavelengths shorter than any of the three Diviner channels used to determine composition, resulting in the concave up spectral shape as emissivity drops at wavelengths longer than the $\mathrm{CF}$ owing to the fundamental $\mathrm{Si}_{-} \mathrm{O}_{2}$ vibrational band.

Lunar Reconnaissance Orbiter Camera - Regions of non-mare volcanism on the Moon generally have relatively higher reflectance than their surroundings (Gillis et al., 2002). Using photometric analysis of LRO Narrow Angle Camera (NAC) images and spectral measurements of laboratory samples, Clegg-Watkins et al. (2017) was able to assess variability in reflectance and composition for several silicic volcanic regions on the Moon. NAC photometry coupled with compositional data from Apollo samples showed that the high reflectance at non-mare volcanic regions is consistent with the presence of silicic materials and low concentrations of mafic minerals. Of the silicic sites studied, the CBVC has the highest reflectance and single scattering albedos, with reflectance values approaching those of exposures of nearly pure anorthosite that have been shown with spectra to be nearly devoid of mafic minerals (Ohtake et al., 2009).

Lunar silicic areas exhibit a range of reflectance values, both within and among the regions, which may have compositional significance. These reflectance variations may be owing to mixing of silicic components, addition of pyroclastic materials, and/or the presence of KREEPy (less silicic) materials (Clegg-Watkins et al., 2017). The reflectance variations are especially evident at the CBVC, where the most reflective regions are small bulges or domes in the central part of the complex. Radar data (Chauhan et al., 2015), the presence of $\mathrm{OH} / \mathrm{H}_{2} \mathrm{O}$ absorptions (Bhattacharya et al., 2013), eastward extension of the Th anomaly (Wilson et al., 2015), laboratory spectra of analog materials (Clegg-Watkins et al., 2017), and the offset between the high-reflectance and elevated topography at the CBVC (Jolliff et al., 2011) indicate the presence of silicic pyroclastics within and around the complex, which also contribute to the increased reflectance.

\section{Implications of Remote Observations}

Evidence from remote sensing data exists for both extrusive and intrusive silicic constructs on the Moon. Based on morphologic characteristics (i.e., steep slopes), Glotch et al. (2010) found that Hansteen Alpha and the Gruithuisen Domes are extrusive volcanic landforms likely composed of rhyolite, whereas Aristarchus and Lassell craters are thought to have excavated silicic lithologies from depth. With the exception of a likely large granitic complex exposed by Aristarchus crater, our evidence for evolved lunar volcanism is limited to several domes or dome complexes (Hagerty et al., 2006; Glotch et al., 2010). The domes, including the far-side CBVC (Jolliff et al., 2011) all appear to be associated with elevated Th concentrations, consistent with the elevated incompatible element concentrations in granitic samples (Seddio et al., 2013). Additionally, lower reflectance values at the CBVC, Hansteen Alpha, the Lassell Massif, and the Gruithuisen Domes may indicate intermediate felsic compositions such as dacite or andesite (Clegg-Watkins et al., 2017), an important result because these rock types have not been observed among the Apollo samples or lunar meteorites. The occurrence of intermediate silicic rocks would require a re-examination of what we know about how silicic rocks form on the Moon, and could indicate that 
previously disregarded pathways to magma evolution occurred (e.g., extended fractional crystallization).

The locations of many of the silicic domes on the lunar surface may provide additional information about their formation mechanism. Many of the silicic constructs fall within the Procellarum KREEP Terrane (PKT), a geologic terrane on the Moon characterized by an enrichment in the incompatible elements that compose the KREEP component. This fertile crust may enable the formation of silicic magma by basaltic underplating (Hagerty et al., 2006). The adjacency of basaltic lava flows to silicic domes lends additional support for the hypothesis of bimodal volcanism and basaltic underplating. However, disparate ages of the silicic domes and surrounding basalt must be considered and may complicate current models for silicic magma generation (Hagerty et al., 2006).

\section{Future Exploration of Silicic Volcanism}

\section{Outstanding questions}

1. Are the spectral signatures seen in Diviner data and photometry owing to silicic material mixing with surrounding material, or do andesitic/dacitic materials occur on the Moon?

2. What role did silicate liquid immiscibility play in the formation of silicic rocks on the Moon?

3. Did basaltic underplating of a fertile crust play a role in the formation of silicic magmas on the Moon? Are the basaltic flows adjacent to silicic constructs on the Moon related petrologically despite their differences in age?

4. What role did the presence of volatiles play in the formation of silicic lithologies?

5. What is the variability in composition of silicic rocks across the Moon?

Answers to these questions address several of the key science priorities outlined in the Scientific Context for the Exploration of the Moon (SCEM) document (NRC, 2007), namely S.2 (The structure and composition of the lunar interior provide fundamental information on the evolution of a differentiated planetary body), $\mathbf{S . 3}$ (Key planetary processes are manifested in the diversity of lunar crustal rocks), and S.5 (Lunar volcanism provides a window into the thermal and compositional evolution of the Moon).

\section{Remote observations needed}

Additional remote observations of silicic bodies are needed with instrumentation optimized to study these lithologies. Hyperspectral thermal IR imagery will provide the most robust determination of silicic anomaly compositions, short of sample return. While Diviner data have been used to identify silicic constructs on the lunar surface, the limited spectral sampling ( 3 narrow CF channels near $8 \mu \mathrm{m}$ ) prevents robust determination of composition. An instrument that provides high spatial ( $\sim 100 \mathrm{~m} /$ pixel) and spectral $\left(\sim 10 \mathrm{~cm}^{-1}\right.$ spectral sampling over 7-25 $\left.\mu \mathrm{m}\right)$ resolution would enable detailed compositional mapping of silicic anomalies, reduce compositional ambiguity, and help determine whether intermediate (e.g., andesite) compositions are present on the lunar surface. Coincident hyperspectral VNIR measurements covering the $3 \mu \mathrm{m}$ band could help determine the role of water in the petrogenesis of silicic rocks on the Moon. Both of these instrument types are suggested as payloads on a large next generation lunar orbiter mission (Glotch et al., 2020). 


\section{Future Surface Science and Sample Return}

Major scientific advances in our understanding of lunar silicic lithologies, their formation and eruption, and their relationship to other lunar rock types, would be enabled by exploration and sample analysis (both in situ and via sample return). Jawin et al. (2019) summarized several community-identified high-priority locations on the Moon for future exploration, which included several regions where silicic rocks may occur: the Gruithuisen Domes, CBVC, and the Aristarchus plateau. Additional locations on the Moon contain evidence of silicic materials that would also be of high priority for exploration, including Hansteen Alpha, the Mairan domes, and Lassell Massif (as discussed above). To fully understand the formation and evolution of silicic bodies on the Moon, detailed sample analyses of both intrusive (e.g., excavated material from Aristarchus) and extrusive (e.g., silicic domes) are needed.

Exploring any of these regions with robotic landers or rovers (or even humans) would facilitate investigations into the composition, age, and structure of lunar silicic materials. These investigations could be accomplished by in situ investigations, including isotopic age determination, gamma ray and neutron detection for volatile abundances, hyperspectral imaging, and determination of bulk chemistry, mineralogy, and volatile content. However, the investigations with the highest precision and accuracy would be possible if samples were returned to Earth for analysis in terrestrial laboratories (Valencia et al., 2020). The detailed petrographic, traceelement chemical, and isotopic analyses possible on Earth will yield unambiguous information on the formation and evolution of the silicic bodies from which they are sampled. Returning silicic samples to Earth also ensures samples can continue to be studied for decades to come as science questions evolve and analytical techniques improve.

\section{Silicic Volcanism Beyond the Moon}

While silicic rocks have been sampled on the Moon, identified spectroscopically on Mars (Christensen et al., 2005), and exist on Venus (Gilmore et al., 2017), their method of production and commonality on planets without plate tectonics remains enigmatic. Measurements to further understand silicic volcanism on the Moon are more approachable than measurements that would likely have to be made on Venus (owing to the challenging environment) and Mars (silicic rocks may be at volcano peaks or buried under basalts). Making these measurements on the Moon can set the foundation for making these measurements on more logistically complex planets. Further study of the distribution, ages, and compositions of silicic rocks on the Moon will better constrain which of these petrogeneses are capable (or if different petrogeneses not found on Earth are possible) on planets that, compared to the Earth, have cooler thermal histories and lack significant tectonism.

\section{Recommendations}

Recommendation \#1: Silicic regions on the Moon should remain a high-priority destination for future sample return. Lunar silicic samples returned from future missions will unambiguously determine the formation mechanism of silicic melts on the Moon, and by extension, provide insights in the thermal evolution and differentiation of the Moon.

Recommendation \#2: Future orbital missions to the Moon should carry instrumentation optimized for the exploration of silicic bodies on the Moon. Additional observations with specialized instruments will reduce the ambiguity of current interpretations of the composition of silicic bodies and would allow for more detailed analyses than possible with current missions. 
Recommendation \#3: We recommend that the decadal survey consider the critical role of team dynamics, equity, diversity, inclusion, and accessibility in planetary science. As demonstrated in this report, the investigation of silicic volcanism in the Solar System requires drawing on perspectives spanning the gamut of planetary science, geoscience, astronomy, technology, engineering, and beyond. Studies of scientific teams have repeatedly demonstrated the importance of an integrated approach, where team members with diverse expertise develop synergies between their specialties and resources that result in an end product that adds up to more than the sum of its parts (Balakrishan et al. 2011). Sociological studies have demonstrated that groups that foster strong connections across sub-units are more innovative with higher impact outcomes that endure (Burt, 2004; Powell et al., 1996; de Vaan et al. 2015).

\section{References}

Balakrishnan, A. D., et al., 2011. Proc. ACM 2011 Conf., 523-532.

Bhattacharya, S., et al., 2013. Curr. Sci., 105 (5), 685-691.

Burt, R. S., 2004. Am. J. of Sociology, 110.

Chauhan, M., et al., 2015. Icarus, 253, 115-129.

Christenen, P. R., et al., 2005. Nature, 436, 504-509.

Clegg-Watkins, R. N., et al., 2017. Icarus. 285, 169-184.

de Vann, M., et al., 2015. Am. J. of Sociology, 120, 1144-1194.

Gillis, J. J. et al., 2002. Lunar Planet. Sci. 33, Abstract \#1967.

Gilmore, M., et al., 2017. Space Sci. Rev., 212(3-4), 1511-1540.

Glotch, T. D., et al., 2010. Science, 329, 1510-1513.

Glotch, T., et al., 2020. Decadal White Paper: A Next Generation Lunar Orbiter Mission

Greenhagen, B. T., et al., 2010. Science, 329, 1507-1509.

Greenhagen, B. T., et al., 2017. Lunar Planet. Sci. XLVIII, Abstract \#2597.

Gullikson, A. L. et al. 2016. Am. Min., 101, 2312-2321.

Hagerty, J. J., et al., 2006. J. Geophy. Res., 111.

Hubbard, N. J., et al., 1971. Proc. Lunar Planet. Sci. Conf., 2, 246.

Jawin, E. R., et al., 2019. Earth Space Sci., 6, 2-40.

Jolliff, B. L., et al., 2011. Nat. Geosci., 4, 566-571.

Jolliff, B. L., et al., 1999. Amer. Mineral., 84, 821-837.

Jolliff, B. L., et al., 2000. J. Geophys. Res., 105, 4197-4216.

Lawrence, D. J., et al., 2003. J. Geophys. Res., 103(E1), 1691-1701.

Lawrence, D. J., et al., 2007. Geophys. Res. Letters, 34, L03201.

NRC, 2007. The Scientific Context for Exploration of the Moon.

Ohtake, M., et al., 2009. Nature, 461, 236-240.

Powell, W. W., et al., 1996. Admin. Sci. Quarterly, 41, 116-145.

Reedy, R. C., et al., 1973. J. Geophys. Res., 78, 5847-5866.

Seddio, S. M., et al., 2013. Am. Min., 98 (10), 1697-1713.

Valencia S. N., et al., 2020. Decadal White Paper: High Priority Sites for Returned Lunar Samples

Whitaker, E. A., 1972. Moon, 4, 348-355. .

Roedder, E., \& P. W. Weiblen, 1972. Proc. Lunar Sci. Conf. 3rd, 251-279.

Valencia et al., 2019. 50th Lunar Planet. Sci. Conf., Abstract \#1433.

Wilson, J. T., et al., 2015. J. Geophys. Res. Planets, 120, 92-108.

Wilson, L., \& J. W. Head, 2003, J. Geophys. Res., 108(E2), 5012.

Wilson, L., \& J. W. Head, 2017. Icarus, 283, 146-175.

Winter, J. D., 2014. Principles of igneous and metamorphic petrology. Pearson education. 